\title{
Survival and complications in a cohort of patients with anti-Delta positive liver disease presenting in a tertiary referral clinic
}

\author{
Robert A. de Man ${ }^{1}$, Renate P. Sprey ${ }^{1}$, Hubert G. M. Niesters ${ }^{2}$, Ruud A. Heijtink ${ }^{2}$, Pieter E. Zondervan ${ }^{3}$, \\ Wim Hop ${ }^{4}$ and Solko W. Schalm ${ }^{1}$ \\ Department of 'Internal Medicine II (Hepatology Section), ${ }^{2}$ Virology, ${ }^{3}$ Pathology and ${ }^{4}$ Biostatistics, University Hospital Dijkzigt and Erasmus \\ University Rotterdam. The Netherlands
}

Background/Aims: Our aim was to evaluate the clinical outcome and survival of patients with anti-Delta positive liver disease in The Netherlands.

Methods: We evaluated those patients visiting our hospital between 1978 and 1993 with respect to clinical, virological and histological parameters. During the follow-up period the occurrence of complications of the liver disease and survival was determined. Thirty patients with a median age of 34 years (range 21-52) were included.

Results: During an average follow up of 4.8 years, nine patients died. The overall 5-year survival as estimated by Kaplan-Meyer analysis was $71 \%$, which was comparable to hepatitis B cirrhosis patients. However, in the group without active hepatitis $B$ replication (HBeAg-negative) a clear trend towards a worse sur-

$\mathrm{T}$ HE DELTA agent was first detected by Risotto et al. in Italy (1). It has been characterized as a defective RNA-virus dependent for infection on the helper functions provided by the hepatitis B virus (HBV) (2). The hepatitis Delta virus (HDV) is thought to be highly pathogenic: inoculation in a chimpanzee model induced liver damage in all recipients (3). HDV can cause acute and chronic liver disease. Two modes of infection have been identified: simultaneous infection with HBV or superinfection of persons already infected by HBV. The outcome of co-infections is most often clearance of both HBV and HDV, whereas superinfections often result in chronic HDV infection, usually progressing to cirrhosis $(2,4-7)$. The diagnosis

Received 19 January; revised $30 \mathrm{May}$; accepted 19 June 1995

Correspondence: R. A. de Man, M.D., Erasmus University Hospital, Department of Internal Medicine II, CA 326, Dr. Molewaterplein 40,3015 GD Rotterdam, The Netherlands. vival was identified in Delta cirrhosis patients. Complications and deaths occurred exclusively in the patient group with cirrhotic liver disease. The complications (ascites, elevated bilirubin $>34 \mu \mathrm{mol} /$ ), variceal bleeding and spontaneous bacterial peritonitis) occurred in $52 \%$ of the patients with a follow up of more than 6 months $(n=27)$. Fifty-seven percent of those patients died. In our population anti-Delta positive liver disease affects predominantly young patients and is related to advanced liver disease.

Conclusions: In view of the high death rate, liver transplantation should be considered when signs or symptoms of decompensated liver disease occur.

Key words: Delta hepatitis; Epidemiology; Survival. (C) Journal of Hepatology. chronic HDV-related liver disease is usually made by detecting a high titer of antibodies against HDV in serum, but recently the polymerase chain reaction (PCR) for HDV-RNA detection in serum has become available. At present the golden standard for the diagnosis is the expression of Delta antigen in liver tissue which can be shown by immunoperoxidase staining. RNA detection in liver tissue is possible by polymerase chain reaction techniques as well as by in situ hybridisation (8-10).

Epidemiological studies show the existence of endemic areas in Southern Europe, the Middle East, parts of Africa and South America $(2,7,11)$. Western Europe and North America are non-endemic areas and almost all Delta infections have occurred in intravenous drug abusers, polytransfused subjects and hemophiliacs (12-16).

The clinical course and survival in Delta patients compare unfavourably with the natural history of chronic $\mathrm{HBV}$ infection $(17,18)$. Although antiviral 
therapy can decrease transaminase activity and decrease the markers of HDV in serum and liver, the overall results are still disappointing $(19,20)$. However, the results of liver transplantation in Delta patients compare favourably with the results in chronic HBV patients. Even after hepatic allograft re-infection with the Delta virus, the survival curve is comparable to the overall survival for non-viral liver diseases (21).

Few clinical studies of Delta hepatitis have been performed in The Netherlands. The aim of our study was to determine the occurrence of complications and survival of a cohort of HBsAg positive, anti-Delta positive patients in a university-based hepatology unit. For comparison, we used a cohort of HBsAg-positive HDV-negative cirrhosis patients concurrently followed in our unit.

\section{Materials and Methods}

\section{Study population}

The Dijkzigt University Hospital serves as a tertiary referral hospital for hepatology and liver transplantation. All patients were referred to our department for evaluation, antiviral therapy and sclerotherapy. Since 1978 , thirty patients with anti-HDV positive liver disease have been diagnosed in our department. The diagnosis of HDV-related liver disease was made by demonstrating $\mathrm{HBsAg}$ and antibodies to the Delta virus. Every patient who had antibodies to Delta on two successive occasions was entered in the study. The clinical situation at presentation was evaluated retrospectively by describing: age, sex, country of origin, ethanol intake and subjective complaints. In addition, signs and symptoms of decompensated liver disease were described: spleen size, presence of ascites, encephalopathy or esophageal varices. Ascites and splenomegaly were diagnosed by physical examination and confirmed by ultrasonography. Esophageal varices were examined by endoscopy or barium swallow, and graded I to IV according to size (22). Hepatic encephalopathy was confirmed by spectral analysis of the electro-encephalogram. Decompensated cirrhosis was defined as a history of variceal bleeding, the presence of ascites, encephalopathy or elevation of bilirubin above $34 \mu \mathrm{mol} /$ 1 (23). Alcohol abuse was defined as a daily alcohol consumption of at least $50 \mathrm{~g} /$ day. Laboratory parameters included: aspartate aminotransferase, bilirubin, albumin, platelets, coagulation factors and the presence of HBsAg, HBeAg (E.I.A., Abbott laboratories, North Chicago, IL, USA) and antibodies to HCV, HAV, HIV, HBsAg, HBeAg and HDV (E.I.A., Abbott laboratories). The presence of antibodies to $\mathrm{HCV}$ was confirmed by recombinant immunoblot assay (Ortho Diagnostics, Raritan, NJ, USA). Aspartate aminotransferase, albumin and bilirubin were measured by the sequential multiple autoanalyzer (12 SMA, Technicon Instruments Corp, Tarrytown, NY, USA). Normotest and thrombotest (Wyegaard and Co., Oslo, Norway) were used as coagulation parameters.

\section{$H D V R N A$}

RNA was extracted essentially as described by Young et al. (24), with some minor modifications. Briefly, to $100 \mu$ l EDTA-plasma, $400 \mu$ lysis buffer was added [4M Guanidinium-iso-thiocyanate, $25 \mathrm{mM}$ sodium-

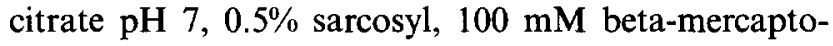
ethanol, $20 \mu \mathrm{g}$ poly $\Lambda$ per $\mathrm{ml}]$. After briefly mixing the solutions, the samples were incubated for $10 \mathrm{~min}$ at $65^{\circ} \mathrm{C}$. The samples were cooled for $1 \mathrm{~min}$ at $0^{\circ} \mathrm{C}$ and $500 \mu \mathrm{l}$ isopropanol was added. The solution was mixed and centrifuged directly for $20 \mathrm{~min}$ at $12000 \mathrm{~g}$ at room temperature. The pellet was washed once with $80 \%$ ethanol and air dried. After adding $30 \mu \mathrm{l}$ DEPC treated bidest, $10 \mu \mathrm{l}$ was used for the cDNA reaction.

Total RNA was denatured for $3 \mathrm{~min}$ at $95^{\circ} \mathrm{C}$ and subsequently chilled on ice. First strand synthesis was performed in a volume of $25 \mu \mathrm{l}$ containing $50 \mathrm{mM}$ Tris$\mathrm{HCl} \mathrm{pH} 8.3,3 \mathrm{mM} \mathrm{MgCl}, 10 \mathrm{mM}$ DTT, $0.5 \mathrm{mM}$ of each of the four dNTPs, $150 \mathrm{U}$ RNasin, $0.25 \mu \mathrm{g}$ hexanucleotides [Promega] and $200 \mathrm{U}$ MMLV reverse transcriptase [Gibco-BRL]. After incubation for $30 \mathrm{~min}$ at $42^{\circ} \mathrm{C}$, the cDNA was incubated for $5 \mathrm{~min}$ at $95^{\circ} \mathrm{C}$. For the reaction, $75 \mu \mathrm{lmix}$ was added containing $10 \mathrm{mM}$ Tris- $\mathrm{HCl} \mathrm{pH} 8.3,50 \mathrm{mM} \mathrm{KCl}, 2.5 \mathrm{mM} \mathrm{MgCl}_{2}, 0.1$ $\mathrm{mM}$ of each of the four dNTPs and $1 \mathrm{U}$ Taq DNA polymerase [Promega] and 50 pmol of primer 1 and 2 [primer 1, position 851-871: CGG.ATG.CCC.AGG.TCG.GAC.CGC; primer 2, position 1275-1298: GGA.TCA.CCG.ACG.AAG.GAA.GGC.CCT. After 4 min incubation at $94^{\circ} \mathrm{C}$, forty cycles were performed in a Biomed thermocycler 60 [Tecnolab, The Netherlands] with $1 \mathrm{~min}$ at $94^{\circ} \mathrm{C}, 2 \mathrm{~min}$ at $48^{\circ} \mathrm{C}$ and $3 \mathrm{~min}$ at $72^{\circ} \mathrm{C}$ respectively. The PCR product was analyzed on a $2 \%$ agarose gel and electroblotted onto a Hybond $\mathrm{N}+$ membrane [Amersham]. The membrane was hybridized with a ${ }^{32} \mathrm{P}$ end-labelled oligonucleotide [GCG. $\Lambda \mathrm{G}$ G.AGG.TGG.AGA.TGC.CA] probe (position 870889) (25). Positive and negative control samples were included both during sample preparation and during the PCR procedure. The sensitivity of the assay is 1000 genome equivalents $/ \mathrm{ml}$.

\section{Histology}

In 27 patients, a liver biopsy was performed for staging of the liver disease. This was tested by immunoperoxidase staining on paraffin-embedded material for $\mathrm{HBcAg}$ and $\mathrm{HBsAg}$ in 22 cases and for the presence 
of HDAg in 24 patients. The polyclonal anti-Delta serum was kindly provided by Organon Tecnika (Boxtel, The Netherlands). Positive control slides were prepared from liver tissue kindly provided by Prof. F. Negro (Molinette Hospital, Turin, Italy). The negative control slides were prepared from a liver explant specimen of an HBsAg-negative patient. The histologic diagnosis was made by two independent histopathologists according to international criteria (26).

\section{Analysis}

The characteristics of the patients were determined at the time of presentation at our unit. The clinical evaluation was repeated every 3-4 months. The follow up started at the time antibodies to the Delta virus were detected, which was at admission to our hospital in all but one case. The follow up closed at 01-01-1993. Survival analysis was done according to the Kaplan-Meier method. To determine the prognosis of patients with anti-Delta positive liver cirrhosis, their survival was compared to a cohort of HBsAg-positive HBeAg-negative patients with cirrhosis concurrent followed in our unit and described previously (23). Patients who had a follow up of more than 6 months were evaluated for their complications and clinical outcome.

\section{TABLE 1}

Initial clinical characteristics of 30 anti-Delta positive patients

\begin{tabular}{lc}
\hline & Number of patients $(\%)$ \\
\hline $\begin{array}{l}\text { Sex } \\
\text { Male/female }\end{array}$ & $25 / 5(83 / 17)$ \\
Country of origin & $17(57)$ \\
$\quad$ Mediterranean & $12 / 1 \quad(40 / 3)$ \\
$\quad$ Western Europe/Eastern Europe & \\
Alcohol intake & $11(37)$ \\
$>5$ drinks/day & $19(63)$ \\
$<5$ drinks/day & \\
Icteric presentation & $9(30)$ \\
Present & $21(70)$ \\
Absent & \\
Ascites & $3(10)$ \\
Present & $27(90)$ \\
Absent & \\
Encephalopathy & $2(7)$ \\
Present & $28(93)$ \\
Absent & $10(33)$ \\
Esophageal varices & $5(17)$ \\
Grade I-II & $8(27)$ \\
Grade III-IV & $7(23)$ \\
Absent & \\
Not investigated & $5(25)$ \\
Spleen size (cm) & $15(75)$ \\
$\leq 12$ &
\end{tabular}

\section{Results}

\section{Entry characteristics}

The characteristics at entry to the study are shown in Tables 1 and 2. Symptomatic disease was present in 27 patients: subjective complaints included nausea, fatigue and upper abdominal pain in the liver region.

The median age at presentation was 34 years (range 21-52 years). Symptoms suggestive of portal hypertension were found in $75 \%$ ( 15 out of 20 had splenomegaly $>12 \mathrm{~cm}$ ). Esophageal varices grade I-II were detected in ten, and grade III-IV in five patients, respectively. The absence of varices was documented in eight patients.

Risk factors for contracting HDV infection were: stay in an endemic area (Mediterranean) in 60\% (18 out of 30), and (ex) intravenous drug abuse in $30 \%$ ( 9 out of 30$)$. In three Dutch patients $(10 \%)$ no risk factors were found. Seven patients had more than one risk factor. HBeAg was found in $10 \%$, and $61 \%$ tested antiHBe positive (tested 29 and 28 patients, respectively). Antibodies to $\mathrm{HCV}$ were positive in $23 \%$ (7 out of 30 ) and $15 \%$ ( 2 out of 13 ) had antibodies to HIV.

\section{Survival analysis}

Thirty patients had a mean follow-up period of 4.8 years (range 1 day-20 years). One patient was lost to follow up. Eight out of nine patients who died during follow up, died due to liver-related causes: liver failure (3), variceal bleeding (2), liver failure after liver trans-

\section{TABLE 2}

Initial virological and biochemical characteristics of 30 anti-Delta positive patients

\begin{tabular}{lccc}
\hline & $\begin{array}{c}\text { Number of } \\
\text { patients }(\%)\end{array}$ & Median & Range \\
\hline Bilirubin $(\mu \mathrm{mol} / 1)$ & $24(80)$ & 12 & $4-339$ \\
$\leq 35$ & $6(20)$ & & \\
$>35$ & & 42 & $24-49$ \\
Albumin (g/l) & $22(73)$ & & \\
$>35$ & $6(20)$ & & \\
$28-34$ & $2(7)$ & & \\
$<28$ & & 56 & $23-300$ \\
AST (IU/I) & $2(7)$ & & \\
$\leq 30$ & $28(93)$ & & \\
$>30$ & & & \\
Thrombotest (\%) & $22(88)$ & & \\
$>35$ & $3(12)$ & & \\
$<30$ & & & \\
Virology & $29(97)$ & & \\
HBsAg positive (tested $n=30)$ & $3(10)$ & \\
HBeAg positive (tested $n=29)$ & $17(61)$ & \\
Anti-HBeAg positive (tested $n=28)$ & $30(100)$ & \\
Anti-HBcAg positive (tested $n=30)$ & $7(23)$ & \\
Anti-HCV positive (tested $n=30)$ & $2(15)$ & \\
Anti-HIV positive (tested $n=13)$ & & \\
\hline
\end{tabular}


TABLE 3

Complications and deaths in 27 anti-Delta positive patients with follow up more than 6 months, according to their initial histological diagnosis

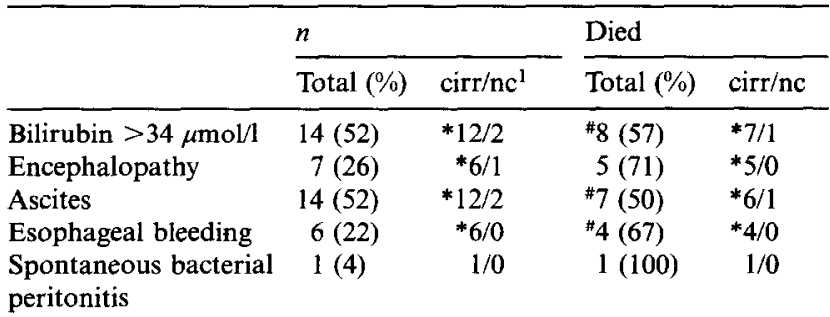

${ }^{1}$ Cirrhosis/non-cirrhosis. ${ }^{*}$ One patient never had a biopsy, he had clinical signs of a decompensated cirrhosis. \# One patient with cirrhosis has died since the end of the follow up (not included in death rates in the table).

\section{TABLE 4}

Correlation between the presence of HDV-RNA in serum as measured by the polymerase chain reaction and immunohistochemistry for Delta-antigen on liver biopsy material

\begin{tabular}{llll}
\hline HDV-RNA PCR & \multicolumn{3}{l}{ Liver immunohistochemistry } \\
\cline { 2 - 4 } & Positive & Negative & No material \\
\hline Positive & 17 & 4 & 5 \\
Negative & 1 & 2 & 1 \\
\hline
\end{tabular}

plantation (hepatic artery thrombosis in one and primary non-function in one) and hepatocellular carcinoma (1). Only one patient died of non-liver-related causes (stomach carcinoma) (Table 3).

The survival of all patients with anti-HDV positive cirrhosis was calculated and compared to a cohort of HBsAg positive cirrhosis patients. The 5-year survival was $71 \%(95 \%$ confidence interval $53 \%-89 \%)$.

The 5-year survival of all $\mathrm{HBeAg}$-negative antiDelta positive patients with cirrhosis $(n=18)$ is compared to HBcAg-negative cirrhosis paticnts in Fig. 2. Although there is a clear trend towards a decreased survival in the Delta patients, statistical significance was not reached, possibly due to the relatively small sample of anti-Delta positive patients.

\section{Histology}

A liver biopsy was performed in 27 patients: cirrhosis was present in $66 \%$ (18 out of 27 ), all with chronic active hepatitis (CAH) as a sign of active disease. According to the Child-Pugh classification, 15 patients were graded as Child A, two patients as Child B and one patient as Child $\mathrm{C}$. Chronic active hepatitis was present in six patients, and chronic persistent hepatitis in two. One patient presented with acute hepatitis in transition to chronic hepatitis.
Immunohistochemistry was done in 24 patients: Delta antigen in liver tissue was positive in $75 \%$. HBsAg and HBcAg in the liver were positive in $95 \%$ and $14 \%$, respectively. One patient was positive for all markers. The polymerase chain reaction additionally detected HDV-RNA in serum in four patients who were negative for HDAg in the liver by immunoperoxidase staining (Table 4). One patient was negative in the HDV PCR in serum, but positive in the immunoperoxidase staining in the liver biopsy.

In the group of nine patients with non-cirrhotic liver disease at presentation, the biopsy was repeated in five: four developed cirrhosis during follow up, one patient still had chronic active hepatitis. At the end of the follow-up period, $81 \%$ showed cirrhosis. The patients who

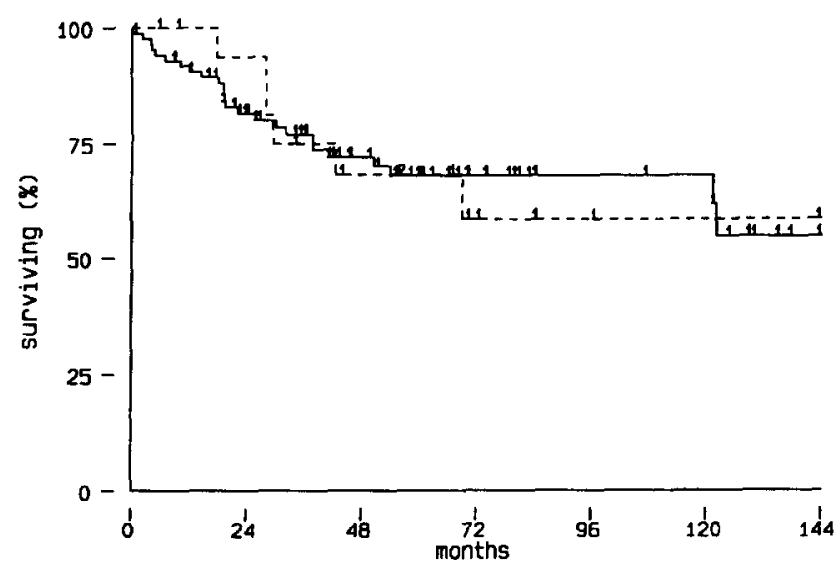

Fig. 1. Survival of all $H B V$ cirrhosis patients (solid line; $\mathrm{n}=86$ ) versus survival of all HDV cirrhosis patients (dotted line; $\mathrm{n}=18$ ). The two survival curves do not significantly differ from each other. Tick-marks along curves represent follow up of patients still alive.

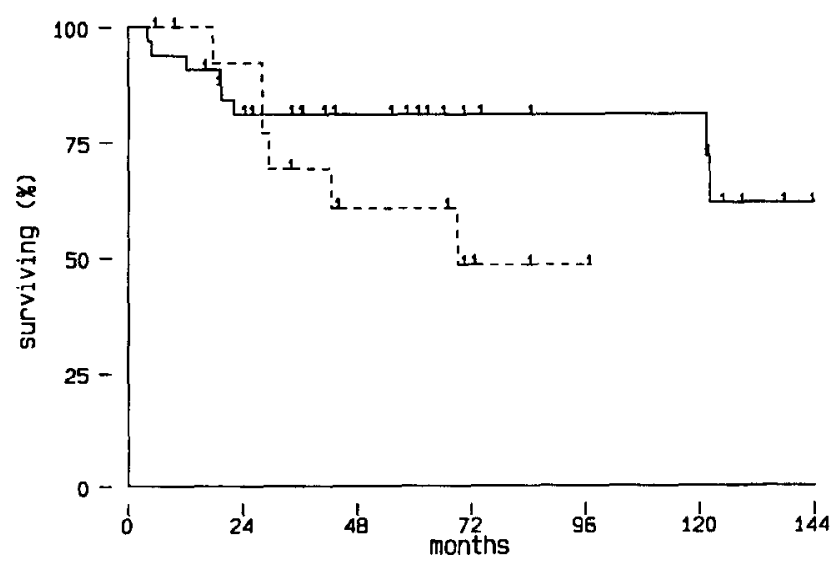

Fig. 2. Survival of patients without active $H B V$ replication (HBeAg-negative) for $H B V$ cirrhosis (solid line; $\mathrm{n}=33$ ) versus HDV cirrhosis (dotted line; $\mathrm{n}=15$ ). 
showed progression to cirrhosis had chronic persistent hepatitis $(n=2)$, acute hepatitis in transition to chronic hepatitis $(n=1)$ and moderate chronic active hepatitis $(n=1)$ at presentation.

\section{Complications}

Of patients with a follow up of more than 6 months, $52 \%$ (14 out of 27 ) developed complications, most frequently icteric episodes (bilirubin $>34 \mu \mathrm{mol} / \mathrm{l}$ ) and the development of ascites (Table 3 ).

Of five patients with esophageal varices grade IIIIV at presentation, three $(60 \%)$ died and two patients with liver transplantation survived. Of ten patients with varices grade $I-I I$, two $(20 \%)$ died. Five patients without varices at presentation $(n=8)$ developed varices (grade I-II) during follow up. Three ( $38 \%$ ) patients died, two had no further investigation and one had no detectable varices.

\section{Discussion}

In The Netherlands, we found anti-Delta positive liver disease in young people who are (ex)intravenous drug abusers and people who have immigrated from the Mediterranean area. This is in accordance with the expected low incidence of the Delta virus in Western Europe.

The results of this study show a 5-year survival of $71 \%$ of anti-Delta positive patients with chronic liver disease after the first presentation in our hepatology unit. This is comparable to a 5-year survival of $80 \%$ in chronic HBV patients. Furthermore, there was no difference in the main causes of death in anti-Delta positive patients and patients with chronic HBV infection $(23,27,28)$. However, if corrected for the presence of $\mathrm{HBeAg}$, a clear trend towards a worse survival in chronic HDV patients was found. This is even more remarkable if the median age of 34 years in taken into account, which is 10 years less than in our HBV cohort. Whether this is due only to the HDV infection or related to confounding factors related to intravenous drug abuse (HCV co-infection (23\%), alcohol abuse $(37 \%))$ cannot be established because of the small size of the cohort.

Ninety-five percent of patients had elevated AST levels $(>30 \mathrm{IU} / \mathrm{I})$ independent of the expression of Delta antigen in the liver. Patients negative for the antigen had higher levels than patients positive for the antigen. Immunological activity while viral replication with expression of the Delta antigen has already ceased might be responsible for the hepatitis in patients negative for the expression of Delta antigen in the liver. This is supported by the detection of Delta RNA by PCR in these patients. In one patient no Delta RNA could be detected by PCR while liver immunohistochemistry was positive. This unexpected result could be explained in several ways: the PCR was performed on stored serum, RNA could have deteriorated during storage or the amount could have bcen below the detection limit of the PCR assay.

The complications of anti-Delta positive liver disease in this cohort were the development of ascites, an increase in bilirubin ( $>34 \mu \mathrm{mol} / 1$ ), encephalopathy and esophageal variceal bleeding. Of the patients who had a follow up of more than 6 months, $52 \%$ developed complications; all patients had cirrhosis at that time. Of these patients, $57 \%$ died during the follow-up period.

We conclude that patients with anti-Delta positive liver disease as they presented in our hospital have a progressive liver disease leading to decompensated liver cirrhosis approximately 10 years earlier than our HBV patients. When decompensated liver disease has developed, liver transplantation is the option of choice, especially since re-infection with Delta hepatitis of the liver allograft does not affect patient or graft survival.

\section{References}

1. Rizzetto M, Canese MG, Arico S, Crivelli O, Trepo C, Bonino $F$, Verme $G$. Immunofluorescence detection of a new antigen-antibody system ( $\delta /$ anti $\delta$ ) associated to the hepatitis B virus in the liver and the serum of HBsAg carriers. Gut 1977; 18: 997-1003.

2. Rizzetto M. The Delta agent. Hepatology 1983; 5: 729-37.

3. Rizzetto M, Canese MG, Gerin JL, Londen WT, Sly DL, Purcell RH. Transmission of the hepatitis B virus-associated Delta antigen to chimpanzees. J Infect Dis 1980; 121: 590602.

4. Smedile A, Dentico P, Zanetti A, Sagnelli E, Nordenfelt E, Actis GC, Rizzetto $M$. Infection with the Delta agent in chronic HBsAg carriers. Gastroenterology 1981; 81: 992 7.

5. Rizzetto M, Verme G, Recchia S, Bonino F, Farci P, Arico S, Calzia R, Picciotto A, Colombo M, Popper H. Chronic hepatitis in carriers of hepatitis B surface antigen with intrahepatic expression of the Delta antigen. Ann Intern Med 1983; 98 : 437-41.

6. Popper H, Thung SN, Gerber MA, Hadler SC, de Monzon M, Ponzetto A, Anzola E, Rivera D, Mondolfi A, Bracho A. Histologic studies of severe Delta agent infection in Venezuelan indians. Hepatology 1983; 3: 906-12.

7. Hadler SC, de Monzon M, Ponzetto A, Anzola E, Rivero D, Mondolfi A, Bracho A, Francis DP, Gerber MA, Thung S. Delta infection and severe hepatitis. Ann Intern Med 1984, 100: 339-44.

8. Cariani E, Ravaggi A, Puoti M, Mantego G, Albertini A, Primi D. Evaluation of hepatitis Delta virus RNA levels during interferon therapy by analysis of polymerase chain reaction products with a nonradioisotopic hybridization assay. Hepatology 1992; 15: 685-9.

9. DiBisceglie AM, Negro F. Diagnosis of hepatitis delta virus infection. Hepatology: 1989; 10: 1014-16. 
10. Negro F, Bonino F, DiBisceglie A, Hoofnagle JH, Gerin J. Intrahepatic markers of hepatitis Delta virus infection: a study by in situ hybridization. Hepatology; 1989; 10: 916-20.

11. Purcell RH, Gerin JL. Epidemiology of the delta agent: an introduction. In: Verme G, Bonino F, Rizzetto M, eds. Viral hepatitis and delta infection. New York: Allan R. Liss; 1983: 113-9.

12. Hansson BG, Moestrup T, Widell A, Nordenfelt E. Infection with Delta agent in Sweden: introduction of a new hepatitis agent. J Infect Dis 1982; 146: 472-8.

13. Raimondo G, Gallo L, Ponzetto A, Smedile A, Balbo A, Rizzetto M. Multicentre study of prevalence of HBV-associated Delta infection and liver disease in drug-addicts. Lancet 1982; (i): 249-51.

14. Rizzetto M, Purcell RH, Gerin JL. Epidemiology of HBVassociated Delta agent: geographical distribution of antiDelta and prevalence of polytransfused BHsAg carriers. Lancet 1980 ; i: $1215-8$.

15. Weller IVD, Karayiannis P, Lok ASF, Montano L, Bamber M, Thomas HC, Sherlock S. Significance of Delta agent infection in chronic hepatitis B infection: a study in British carriers. Gut 1983; 24: 1061-3.

16. Roggendorf M, Gmelin K, Zoulek G, Wolf P, Schlipköter U, Jilg W, Theilmann L, Deinhardt F. Epidemiological studies on the prevalence of hepatitis Delta virus infections in the Federal Republic of Germany. J Hepatol 1986; 2: 230-6.

17. de Cock KM, Govindarajan S, Chin KP, Redeker AG. Delta hepatitis in the Los Angeles area: a report of 126 cases. Ann Intern Med 1986; 105: 108-14.

18. Smedile A, Farci P, Verme G, Gargnel A, Dentico P, Oplon P, Vergani D, Williams R, Rizzetto M. Influence of Delta infection on severity of hepatitis. B. Lancet 1982; ii: 945-7.

19. Rizzetto M, Chiaberge E, Negro F, Di Giacomo C, Cortesini R, Doglia M, Macagno S, Verme G, Marinucci G, Alfani D,
Milazzo F, Fassati LR, Galmarini D. Liver transplantation in hepatitis Delta virus disease. Lancet 1987; ii: 469-71.

20. Farci P, Mandas A, Coiana A, Lai ME, Desmet V, van Eyken P, Gibo Y, Caruso L, Scaccabarozzi S, Criscuolo D. Treatment of chronic hepatitis $D$ with interferon alfa-2a. N Engl J Med 1994; 330: 88-94.

21. Samuel D, Muller R, Alexander G, Fassati L, Ducot N, Benhamou JP, Bismuth H. Liver transplantation in European patients with the hepatitis B surface antigen. N Engl J Med 1993; 329: 1842-7.

22. Giani AZ, Van Buuren HR, Hop WCJ, Schalm SW. Oesophageal varices: how reliable is a barium swallow? $\mathrm{Br} J$ Radiol 1993; 66: 322-6.

23. Jongh F, Janssen HLA, Man RA de, Hop WCJ, Schalm SW, van Blankenstein $\mathbf{M}$. Survival and prognostic indicators in hepatitis B surface antigen-positive cirrhosis of the liver. Gastroenterology 1992; 103: 1630-5.

24. Young KK, Resnick RM, Myers TW. Detection of hepatitis $C$ virus RNA by a combined reverse transcription-polymerase chain reaction assay. J Clin Microbiol 1993; 31: 8826.

25. Chao YC, Chang MF, Gust I, Lai MM. Sequence conservation and divergence of hepatitis delta-virus RNA. Virology 1990; 178: 384-92.

26. Schlichting P, Fauerholt L, Christensen E, Poulsen H, Juhl E, Tygstrup N. Clinical relevance of restrictive morphological criteria for the diagnosis of cirrhosis in liver biopsies. Liver 1981; 1: 56-61.

27. Liaw YF, Lin DY, Chen TH, Chu CM. Natural course after development of cirrhosis in patients with chronic type $B$ hepatitis: a prospective stuy. Liver 1989; 9: 235-41.

28. Ginés P, Quintero E, Arroyo V, Teres J, Bruguera M, Rimola A, Rozman C. Compensated cirrhosis: natural history and prognostic factors. Hepatology 1987; 7: 122-8. 